\title{
Historiografia, nação e os regimes \\ de autonomia na vida letrada \\ no Império do Brasil
}

\section{Historiography, Nation and Regimes of Autonomy in the Brazilian Empire's Intellectual Life}

\author{
Valdei Lopes de Araújo \\ Departamento de História \\ Universidade Federal de Ouro Preto \\ R. Salomão de Vasconcelos, 79 Casa 5, São José, Mariana, MG, 35.420-000, Brasil \\ valdei354@gmail.com
}

Resumo Este artigo analisa o surgimento e a evolução de dois regimes de autonomia intelectual no Brasil da primeira metade do século XIX. A análise concentra-se no crescente desejo por história dessa sociedade, e de como esse desejo complexificou e colocou novas exigências ao historiador e sua escrita. Argumenta-se para a existência de dois regimes de autonomia intelectual relacionados a modos distintos de produção do discurso histórico. De um lado, um modo compilatório, que atende a demanda social por sínteses pragmáticas, ligando-se mais profundamente ao mercado editorial e ao mundo emergente de um leitor não -especializado. De outro, um modelo disciplinar que precisou abrir e legitimar sua relação privilegiada com o Estado e suas instituições.

Palavras-Chave regimes de autonomia, escrita da história, modernidade, autoria

\footnotetext{
Recebido: 26 de outubro de 2014 | Aprovado: 2 de abril de 2015

http://dx.doi.org/10.1590/0104-87752015000200004

Varia Historia, Belo Horizonte, vol. 31, n. 56, p. 365-400, mai/ago 2015
} 
Aвstract This article analysis the rise and evolution of two regimes of intellectual autonomy in the first half of $18^{\text {th }}$ century in Brazil. The paper is focused on this society increasing desire for history and how this desire challenged the writing of history and the historian. It argues the existence of two different regimes of intellectual autonomy related to different ways of historical discourse production. From one side, a compilatory regime focused on the social demands for pragmatic synthesis. This regime was more connected to the editorial market and to a emergent non-specialized readership. From de other side, a disciplinary regime concerned with the production of new forms of legitimacy to its relationship with the modern national state and its institutions.

KEYwORDS regimes of autonomy, writing history, modernity, authorship

\section{INTRODUÇÃO}

Na década de 1980 vemos a emergência no Brasil de um campo de estudos voltado para a História da Historiografia. Especialmente preocupado com as origens modernas da união entre escrita da história e formação dos estados nacionais, uma das molas desse campo foi a revisão crítica dos modelos interpretativos nacional-desenvolvimentistas. Questionava-se como ideológica a relação entre escrita da história e nação, acreditava-se na possibilidade de um discurso ideologicamente livre ou, pelo menos, comprometido com um projeto de emancipação. Essa linguagem da crítica ideológica, essencial ao fortalecimento das ciências sociais no Brasil, foi dando lugar, na historiografia, a uma crítica ampla ao discurso da história em geral. A expansão epidêmica da crítica coincidiu com a abertura política e com o crescimento acelerado dos Programas de Pós-graduação em História e Humanidades. Esses fenômenos pareciam confirmar aquilo que Novick chamou de fim da disciplina histórica como um campo, em suas palavras, "Como uma ampla comunidade discursiva, como uma comunidade de pesquisadores unidos por objetivos comuns, padrões comuns, e propósitos comuns, a 
história como disciplina deixou de existir" (Novick, 1988, p.628; apud Zammito, 2009, p.75).

No contexto brasileiro, passamos do que tenho chamado de "linguagem da ideologia" para a "linguagem da invenção" como discurso predominante entre os historiadores, o que contribuiu para dissolver uma longa tradição de perguntar-se pela "modernidade" brasileira em favor de procedimentos descritivistas, concentrados em uma historiografia menos teórica e supostamente mais empírica (Araujo, 2012). Sem abdicar da tarefa de uma reescrita da História da Historiografia atenta aos seus aspectos construídos, acredito que podemos, e de fato estamos, ampliando a agenda de investigação para além do esforço desconstrutivo. Esse deslocamento é importante, dentre outros fatores, pelo fato de a desconstrução não ter sido capaz de romper com os usos e abusos da história e, em certo sentido, ter mesmo aprofundado um tipo de historicização dos mundos da vida que cada vez mais reifica nossa relação com o passado, transformado-o em mais um produto a ser fabricado, distribuído e comprado (Araujo, 2013; Bevernage, 2012; Davies, 2012; Gumbrecht, 2010).

No lugar de tornar a busca pela nação e sua identidade como uma explicação última para a historiografia, podemos apontar condições estruturais capazes de explicar a emergência do desejo por história e por nação, algo que as linguagens da ideologia ou da invenção tiveram dificuldade de produzir até agora, insistindo em uma espécie de ontologia presentista em que apenas o presente tem realidade, sendo o passado e o futuro apenas projeções prospectivas e retrospectivas.

O que as pesquisas mais recentes parecem demonstrar é que o IHGB e a escrita da história no século XIX não eram apenas, nem principalmente, fábricas de ideologias. Um olhar mais detido sobre o processo de formação do discurso histórico moderno revela movimentos intencionais e não-intencionais de autonomização da prática historiadora e intelectual. Esse movimento em direção a padrões modernos de autonomia não é capaz de esgotar a complexa diversidade da vida intelectual oitocentista, mas certamente foi um traço estruturante da maior relevância. Portanto, devemos compreender que os fenômenos e processos 
históricos que impulsionavam em direção à disciplinarização eram, ao mesmo tempo, os que possibilitavam e restringiam o novo padrão de autonomia em formação. Insisto na ideia de limite para não produzir a falsa imagem de um "projeto" sistematicamente perseguido, mas um movimento histórico que se configurou entre evento e estrutura.

Longe de ser um movimento linear e homogêneo, a construção do discurso histórico moderno foi marcada por diferentes processos, muitos deles contraditórios. Neste artigo, tentaremos analisar dois padrões de autonomia da produção historiográfica moderna, o primeiro, que chamarei de compilatório, e o segundo, disciplinar. Identificar as condições de emergência desses diferentes padrões é fundamental para a compreensão do sentido e alcance das obras, bem como para a compreensão dos limites da experiência da história disponível nas sociedades que demandaram e se constituíram a partir desses padrões.

Compilatório e disciplinar são aqui utilizados como duas categorias que apontam para fenômenos históricos bastante complexos, certamente fariam sentido para muitos dos sujeitos históricos envolvidos neste processo, embora certamente não com o grau de abstração com que as desenvolvemos. Em especial a categoria disciplinar deve ser entendida com maior cautela, pois para nós serve como resumo de um longo percurso histórico que do ponto de vista de sua realização pode parecer linear e coerente, mas que nos diferentes momentos históricos é mais ambíguo. Da mesma forma, a hegemonização de um padrão não deve ser entendido como a simples substituição dos modelos concorrentes ou o seu desaparecimento. No caso que tratamos, seria mais prudente falar em acomodações competitivas em diferentes arranjos.

A seguir, tentaremos compreender a existência e dinâmica desses regimes de autonomia em sete partes ou cenas. Em cada cena analisaremos momentos de polêmica e disputa discursiva em torno do lugar, funções e limites do historiador e da escrita da história. Ao final, esperamos poder deixar no leitor a impressão da permanência de um diálogo em torno dos limites da representação do passado no século XIX, e de como nesses diálogos conflituosos podemos melhor entender os modos de produção e a diversidade da historiografia moderna. 


\section{Cena I. Moraes Silva, Agostinho de Macedo E Hipólito José da Costa: COMPILAÇÃo, MOdernidade E CRise Na história de Portugal}

A história geral de Portugal mais influente até a obra de Alexandre Herculano, cujo primeiro volume data de 1846, foi extraída e continuada de um projeto coletivo de História Universal compilada para o mercado editorial britânico na segunda metade do século XVIII. Traduzida para diversos idiomas nacionais europeus, a "Universal History" serviu de base para várias outras "histórias nacionais" em um contexto onde as pessoas e governos desejavam ter seu passado ao alcance das mãos. ${ }^{1} \mathrm{No}$ caso Português, essa transposição começou com a tradução feita pelo brasileiro Antônio Moraes Silva, publicada em 1788. O mesmo Moraes Silva, em 1789, publicaria uma compilação sintética e modernizada do vetusto e enciclopédico dicionário latino e português de Rafael Bluteau. Com a "História de Portugal" o esforço de Moraes não foi de síntese, mas analítico, tanto traduzindo e anotando o ensaio de história filosófica acrescentado na edição francesa da "Universal History", quanto avançando na cronologia ao adicionar novos capítulos ao texto original.

Graças ao trabalho pioneiro do historiador italiano Guido Abbatista podemos hoje vislumbrar a importância da "Universal History" para a história intelectual do século XVIII (Abbatista, 1985). Ofuscada por projetos de fortuna crítica mais rica como a Encyclopédie, a iniciativa britânica de uma grande história universal, apesar de ter sido muito influente e traduzida para diversas línguas entre os séculos XVIII e XIX, acabou por afundar em relativo esquecimento. ${ }^{2}$

Antes de tudo um projeto comercial voltado para o florescente mercado do livro, as partes antiga e moderna da Universal History estão

1 Esta questão está amplamente desenvolvida em ARAUJO, Valdei Lopes de; RAMOS, André. A emergência de um ponto de vista cosmopolita: a experiência da História de Portugal na Universal History. (no prelo).

2 Atualmente, alguns pesquisadores tem abordado a questão: ZANDE, 2003; LINL, 2006; BAÁR, 2010. 
separadas pelas grandes transformações do século XVIII, já que a obra anunciada em 1729 teve a primeira parte, História Antiga, publicada entre 1736 e 1744, e a segunda, História Moderna, entre 1759 e 1765. Os letrados reunidos pelos editores britânicos ilustravam um novo tipo de profissional da erudição disposto a atender as demandas de um empreendimento que pressupunha certo gosto pelo risco. George Sale, John Swinton, George Shelvocke, George Psalmanazar, John Campbell, Tobias Smollett, dentre outros, representavam um tipo de letrado muito diferente dos sisudos eruditos reunidos nas academias régias do Antigo Regime. Nenhum deles terá a evidência dos grandes Philosophes do século XVIII, mas alguns como Campbell e Sale saberiam como poucos explorar o mercado editorial em expansão (Abbatista, 2001, p.102). Coube a Campbell, dentre outras seções, compilar a História de Portugal a partir de relatos de cronistas, historiógrafos e histórias eclesiásticas.

Mesmo admitindo a pluralidade de um projeto que atravessou boa parte do século XVIII, alguns apontamentos podem ser feitos no sentido de ampliar nossa compreensão sobre o seu significado para a modernização da experiência da história (Araujo; Pimenta, 2008; Costa, 2010). Em primeiro lugar, o projeto produziu, com algum grau de consciência da parte dos editores, uma revisão em escala inédita da experiência da História Universal até então disponível. Gênero muito antigo, cuja história é certamente marcada por grandes descontinuidades, tinha, na época moderna, na unidade do mundo cristão e de sua história providencial uma de suas bases de sustentação. O projeto britânico nasceu do diagnóstico da insuficiência desses modelos, buscando novas direções.

Ao reunir, traduzir e compilar as diversas histórias para forjar as histórias nacionais e, no limite, uma história universal que coincidia com o próprio globo, projetos como o da "Universal History" davam concretude e realidade à experiência moderna da história como um singular coletivo. A prática compilatória, permitida por um modelo de autoria ainda difuso, colaboraria para o aprofundamento da experiência moderna e, de modo ambíguo, para a emergência de novos padrões historiográficos e autorais que depois colidiriam com a prática compilatória. É bastante sintomático o exemplo da já citada compilação feita 
por Moraes do dicionário de Bluteau. Na primeira edição, de 1789, é ainda o nome do padre que aparece como autor da obra, já na segunda, de 1813, Moraes sente a necessidade, ou o direito, de figurar como autor.

$\mathrm{Na}$ escrita da história a compilação atendia a demandas por democratização do conhecimento sobre o passado, mas da forma como praticada na "Universal History" pressupunha certo horizonte estável em sua representação. Acreditava-se que uma só história poderia surgir da colaboração de diversos autores, e que essa mesma história seria simplesmente continuada em direção ao presente, com novos capítulos e seções. E, de fato, foi isso o que aconteceu ao longo de diferentes edições da coleção ou das histórias nacionais destacadas do conjunto, como o caso da "História de Portugal".

No inicio do século XIX teremos ainda mais duas edições ou continuações dessa "História de Portugal" extraída da matriz produzida por Campbell. Uma organizada por José Agostinho de Macedo em 1802, na qual acrescentou um capítulo sobre o reinado de Dona Maria I, e outra, em 1809, editada por Hipólito José da Costa. Na edição de Hipólito, pela primeira vez, no lugar de simplesmente continuar expandindo o projeto, o editor sentiu a necessidade de reescrever a parte dedicada ao reinado de Dona Maria I, substituindo o capítulo de Agostinho de Macedo por um de sua própria autoria. Esse episódio talvez seja o documento mais evidente de como a crise da representação e as transformações na experiência da história problematizariam esse modelo de escrita, levando tanto a uma nova concepção de autoria, quando à necessidade moderna de contínua reescrita da história. ${ }^{3}$ No prefácio, iniciando a primeira polêmica que trataremos neste artigo, Hipólito justifica a atitude inesperada:

A Grande aceitação que tivera este resumo da História de Portugal, fez com que se desejasse, nesta nova edição, um aditamento, que compreendesse a história do Reinado de D. Maria I, que Deus guarde; incumbiuse-me esta tarefa; e não podendo eu fazer resumo de uma história que

3 ARAUJO, Valdei Lopes de; RAMOS, André. A corrosão historicista em duas versões da história do reinado de D. Maria I. (no prelo). 
ainda ninguém havia escrito, julguei que devia contentar-me, com fazer um esboço, que se assemelhasse ao resumo precedente. Haviam já tentado isto na edição de Lisboa de 1802, mas eu julguei que devia seguir outra vereda, e tocar muitos fatos, que naquele compendio se omitiram; dando a outros uma forma algum tanto diferente do que ali se acha. $\underline{\mathrm{O}}$ Público decidirá, qual destes epitomes se aproxima mais ao verdadeiro e ao imparcial; os mesmos fatos tocam diferentemente, diferentes pessoas, e cada um os refere, segundo a impressão, que lhe fazem. ${ }^{4}$

Vários temas que serão mobilizados a frente são reunidos neste pequeno fragmento. A diversidade dos pontos de vista devido à velocidade crescente das transformações que tornavam a história do presente um campo de batalhas, as incertezas quanto à capacidade do escritor em manter a imparcialidade, e os leitores ou público como tribunal decisivo. Seja no presente ou na posteridade, o leitor é peça central no juízo das diferentes versões da história que agora parecem ser inevitáveis. Neste cenário, a autoria passou a ser um elemento constitutivo da própria representação, já que esse ponto de vista único alterava as impressões acerca dos mesmos fatos.

\section{CENA II. O Fim do “ANTIGo SISTEMA COLONIAL” E A HISTORIOGRAFIA JOANINA NO BRASIL: Casal, Cairu, Gonçalves dos Santos e Southey}

Ao longo do século XVIII, em especial na segunda metade, o interesse pela história vai se ampliando, da mesma forma em que se ampliavam as camadas da realidade que passavam a exigir algum tipo de tratamento histórico-temporal. Mesmo as monarquias absolutas como a portuguesa precisavam produzir um discurso histórico legitimador que fosse além

4 COSTA, Hipólito José da. Prefácio a esta Edição. In: História de Portugal composta em Inglês por uma sociedade de Literatos. Transladada em vulgar com as notas da edição francesa, e do tradutor francês Antonio de Morais da Silva e continuada até os nossos tempos. Em Nova Edição: Tomo I. Londres: Na Oficina de F. Wingrave, T. Boosey; Duau \& Co \& Lackington; Allen \& Co, 1809, p.VII. (Grifo nosso) 
dos cânones das antigas crônicas e histórias dinásticas. Esses estados monárquicos precisavam responder a grande pergunta do mundo político moderno: estamos na direção histórica correta? Qual o futuro dessa unidade cada vez mais frágil chamada Império Português? Não por acaso, a escrita da história, ao lado da economia política, foram as grandes preocupações do reformismo ilustrado também no mundo luso-brasileiro (Pimenta, 2011).

Ao desembarcar no Brasil em 1808, a Corte portuguesa, e parte considerável dos dirigentes do Império, sabiam que o passado local deveria ser crescentemente incorporado nesse processo de modernização controlada da experiência da história. Não era possível mais limitar o interesse e os auditórios, era necessário disputar as narrativas. A luta política, cada vez mais feita pela imprensa, confrontava interpretações históricas concorrentes. É nesse sentido que podemos falar no surgimento de uma historiografia joanina no Brasil. Mas diferentemente das histórias dinásticas do Antigo Regime, esses discursos não tinham sua legitimidade garantida pelo aval real ou de academias restritas, eles precisavam disputar legitimidade em espaços cada vez mais plurais.

É neste contexto que podemos interpretar as histórias do Brasil, ou produzidas no Brasil, por autores como Luís Gonçalves dos Santos, Ayres de Casal, José da Silva Lisboa (Cairu), José Bonifácio de Andrade e Silva, Balthazar da Silva Lisboa, dentre outros (Araujo, 2009; 2010; 2010b; Diniz, 2010; Rosa, 2011). Esses relatos tentavam produzir a sensação de que o futuro estava sob controle, que o passado ainda fazia sentido e continha experiências que, apesar de ocultas, poderiam ser revitalizadas na significação do presente. Ao celebrar o reinado de D. João, por exemplo, autores como Cairu e Santos mantinham a antiga ideia de "benefícios" e "liberalidade" real, mas a lista dessas virtudes incluíam cada vez mais ações de abertura da economia e da sociedade, o que eles resumiam na ideia força de que D. João estava promovendo o fim do sistema colonial. ${ }^{5}$

5 Para uma visão das permanências dos valores do Antigo Regime ver o excelente artigo de NEVES, 2011, p.248-249. O que argumento é que a permanência desses valores também provocou efeitos não-visados que ajudaram a corroer o arranjo joanino. 
Do ponto de vista estrutural, essa historiografia joanina permitiu aos homens do Brasil ter à mão sínteses cada vez mais amplas de suas histórias. Mesmo que mobilizadas para produzir adesão afetiva e reconhecimento à autoridade real e ao projeto do Reino Unido, esses textos também produziram o efeito colateral de uma maior visualização das diferenças entre Brasil e Portugal (Araujo, 2008). Também nesse horizonte podemos compreender o grande projeto de uma história do império português desenvolvido pelo historiador britânico Robert Southey. A pesquisa de André Ramos mostrou que a grande História do Brasil publicada por Southey entre 1810 e 1819 era inicialmente parte desse projeto maior. Projetada para defender a unidade do mundo luso, também ela seria utilizada para a construção de uma identidade brasileira distinta da portuguesa. Dividido entre diferentes e dinâmicas expectativas dos ambientes intelectuais britânico e luso-brasileiro, a obra de Southey documentou as ambivalências da modernização do discurso histórico nesse começo de século XIX, bem como revelou a ampla circulação de ideias, conceitos e pessoas que ajuda a explicar a formação dialógica dessas narrativas (Ramos, 2013), muito diferente do modelo da "importação de ideias" tão cara à historiografia centrada na crítica das ideologias.

O projeto reformista, de reconstruir a identidade lusa em termos nacionais em um âmbito imperial, encontrou o seu limite em $1820 \mathrm{com}$ a revolução constitucionalista do Porto. A divisão material do Estado em 1808 deu maior energia ao projeto de uma nação que integrasse as periferias do império, mas a velocidade dos acontecimentos revelou as dificuldades estruturais para produzir uma comunidade de interesses e sentimentos em territórios tão descontínuos. O resultado foi a bifurcação do processo de nacionalização dessas realidades. A partir de 1822 Brasil e Portugal teriam que reconfigurar esse legado em projetos nacionais distintos, afastando a possibilidade de um desenvolvimento análogo ao que produziu o homem britânico ao longo do século XVIII com a convergência de Escócia, Inglaterra e Irlanda (Shields, 2010, p.8; Melton, 2001, posição 1824-1836). 


\section{CENA III. A INDEPENDÊNCIA, UM NOVO ESTADO E SUAS histórias: Beauchamp, Beaumelle, Cairu e Denis}

A nova situação política aberta em 1822 ampliou a liberdade de imprensa e expressão. O modelo do intelectual reformista protegido e acoplado ao Estado, em uma situação de circulação controlada da opinião, deu lugar a um processo selvagem de aprendizado e negociação de autonomias e legitimidades. Essa situação afetaria diretamente as condições para a escrita da história. A necessidade e o desejo por história era crescente, seja do lado da sociedade civil, seja do lado do Estado. A luta pelo reconhecimento da legitimidade da Independência do Brasil levou o governo do agora monarca constitucional a recrutar letrados nacionais e estrangeiros capazes de produzir narrativas da legitimidade nacional.

Do ponto de vista da sociedade, conhecer a história pátria tornava-se um requisito do exercício pleno da cidadania. Os debates nos recém -abertos parlamentos nacionais exigiam dos representantes da nação a capacidade de articular o processo histórico em defesa de suas agendas. O mercado intelectual europeu, em particular o britânico e o francês, viviam um momento de grande demanda por relatos históricos que entretecem e instruíssem um crescente número de leitores nos assuntos históricos das novas nações em surgimento ao redor do mundo. Para o "Homem de Estado", para o Negociante ou mesmo para o cidadão comum, passou a ser fundamental o conhecimento histórico para a tomada de decisão e orientação política, comercial ou existencial. ${ }^{6}$

Relatos como os de De Pradt, Beauchamps, Beaumelle e Ferdinand Denis sobre o Brasil recém-independente tanto alimentavam os mercados europeu e local, quanto atendiam os interesses das classes dirigentes na busca de novas formas de legitimação e orientação. A concepção moderna de autoria enfatizava noções como independência e originalidade. Trabalhos coletivos por encomenda como os que produziram

6 Nenhuma outra obra recente tem documentado tão largamente esse processo quanto os seis volumes da série de livros "Barbarism and Religion", de John Pocock. 
a "Universal History" não deixariam de existir, mas o valor da autoria tendia a se sobrepor ao do artesanato letrado. James Melton observa que na Grã-Bretanha do século XVIII a forte indústria do livro garantiu a diversos autores um tipo de independência ancorada na venda do impresso, o que tornava o vínculo com o estado e suas autoridades algo a ser evitado. Nos casos da França e dos estados alemães, os autores dependiam mais do patrocínio governamental para o financiamento de suas atividades. Como não poderiam abdicar dos novos protocolos da autoria e independência, desenvolveram um discurso e uma "visão transcendente de si mesmos como servidores do bem público", "representantes da opinião pública" (Melton, 2001, posição 1843). Portanto, mesmo em situações em que o mercado do livro não era ainda capaz de garantir sozinho a "sobrevivência" do letrado, outros mecanismo de proteção e separação foram sendo constituídos, claro, não sem questionamentos e limites.

O francês Alphonse Beauchamp talvez tenha sido um dos letrados mais emblemáticos e controversos desse período. Em 1815 publicou sua "História do Brasil", em grande parte uma compilação do trabalho de Southey. Essa história, já traduzida para o português em 1817, autorizou Beauchamp a se autonomear "Historiador do Brasil". Durante as negociações diplomáticas pelo reconhecimento da Independência, o governo brasileiro aparentemente encomendou ao historiador francês uma história da Independência que demonstrasse sua legitimidade, o que resultou no relato intitulado: "A independência do império do Brasil apresentada aos monarcas europeus". Um ano antes, em 1823, os mesmo ministros também teriam contratado Angliviel de La Beaumelle para defender a causa brasileira, o que resultou na publicação de um relato da independência sob o título "Do império do Brasil" (Medeiros, 2012, p.19, 75ss).

Segundo Medeiros, as versões produzidas pelos franceses consolidava a ideia de que a independência não teria sido resultado de uma revolução planejada, mas a única saída do Brasil frente à opressão e injustiça das Cortes. Também o jovem Ferdinand Denis, aparentemente atendendo a uma demanda do mercado, escreveria um primeiro esboço 
de uma história da literatura do Brasil, lançando o projeto de uma Independência cultural. Como se vê, não era muito simples separar os projetos promovidos e financiados pelo estado daqueles que surgiam por interesses autorais ou do mercado do livro e seus novos leitores. $\mathrm{O}$ fato é que se aprofundava o interesse existencial por um novo tipo de história, mais ampla, menos fundada em fórmulas ou exemplos congelados. Metáforas como "diorama”, que conectavam tecnologias de análise da conjuntura histórica, denunciavam o novo campo de experiência disponível (Araujo, 2011). Ao mesmo tempo em que liam os folhetins sentimentais nos rodapés dos jornais, inclusive no Brasil, esses homens precisavam educar também seus sentimentos para compreender o novo mundo histórico em formação. Era preciso desenvolver novas cognições, como a empatia e a simpatia, de modo a compreenderem melhor a alteridade crescente do indivíduo e das nações. Era a busca dessa compreensão que explica o sucesso do projeto lançado por Denis: uma nova nação, uma nova literatura, uma nova história.

\section{Cena IV. 1825-1830: CAIru versus Vergueiro, O QUESTIONAMENTO PÚBLICO DA RELAÇÃO HISTORIADOR E ESTADO ${ }^{7}$}

Em janeiro de 1825, no contexto turbulento de fechamento da Assembleia Constituinte no ano anterior e da luta pelo reconhecimento da Independência, Dom Pedro I incumbe José da Silva Lisboa, o futuro Visconde de Cairu, de escrever a história dos sucessos do Brasil em sua Independência. A ordem determinava ainda que se remetessem documentos autênticos dos Governos das Províncias que pudessem servir de "Seguros Guias" ao relato. Dispensado de suas funções administrativas, Cairu contaria ainda com o auxílio do Frei Francisco de Sampaio e do brigadeiro Domingos Alves Branco Moniz Barreto, ajuda que parece ter ficado apenas nas intenções (Kirschner, 2009, p.267).

7 Sobre o episódio e a historiografia de Cairu, ver: VIANNA, 1963; ARAUJO, 2010; DINIZ, 2010; KIRSCHNER, 2009, p.267-271 e KIRSCHNER, 2010. 
$\mathrm{Na}$ "Introdução" do que intitularia "História dos Principais Sucessos Políticos do Império do Brasil”, Cairu manifestava sua intenção de escrever uma História Geral da nova nação independente. A Introdução explicava as origens e as intenções do projeto, comunicava e solicitava ao público letrado subsídios para a empresa, expondo ainda as linhas gerais que seguiria para o cumprimento da tarefa (Araujo, 2010).

Diferentemente da ordem do Imperador, Cairu planejou escrever uma História Geral completa do Brasil, com um plano para 10 volumes. No projeto, assumia a visão de uma lenta evolução histórica em direção à Independência já visível na obra de Robert Southey, escolhida como "farol" da sua (Diniz, 2010, p.79-80). O primeiro volume da obra, publicado em 1827, trata das Grandes Navegações e do Descobrimento do Brasil, conectando a história nacional com as grandes narrativas ilustradas. Mas o que chama atenção neste e nos outros três volumes publicados é o esforço contínuo de debate e avaliação das narrativas até então disponíveis sobre a história do Brasil. Cairu escreve sua versão ao mesmo tempo em que combate interpretações concorrentes, evidenciando a dificuldade crescente na produção de um relato consensual e estável da história do Brasil.

O esforço de Cairu em conhecer e julgar o que fora escrito ou estava sendo escrito sobre a história do Brasil vai fazer com que, ao longo da obra, cujo último volume é publicado em 1830, ele continue a inserir resenhas críticas. Na "Introdução", que parece ter se avolumado na medida em que novas obras chegavam ao seu conhecimento, ele afirma, sobre um novo livro de De Pradt: "Não se podendo levantar qualquer Edifício sem alimparse a área, não posso abrir mão desta Preparação sem fazer análise, e opor barreira, ao Compêndio histórico do Triennio, que Mr. De Pradt cifrou nessa sua última Obra, de que tenho notícia". ${ }^{8}$ Portanto, sua relação com a história escrita não a confundia com os fatos ou o passado em si mesmo, mas já pressupunha a tarefa de uma constate reavaliação das interpretações disponíveis e, como consequência lógica, sua contínua reescrita.

8 LISBOA, José da Silva. História dos Principais Sucessos Políticos do Império do Brasil, vol.1. Rio de Janeiro: Tipografia Nacional, 1825-1830, p.28. 
A partir desse ponto, o trabalho crítico confunde-se com a luta política contemporânea. Nos quatro volumes publicados da obra, Cairu acrescentará anexos, novos prefácios e notas explicativas para se pronunciar sobre os novos relatos publicados. A partir do volume 3, que já narra os acontecimentos de $1822 \mathrm{em}$ diante, a obra vai assumindo o caráter de uma quase crônica, um depositório de documentos autênticos. Lisboa reclama da dificuldade em se estabelecer as causas reais para os acontecimentos; seja pela divergência de opinião, seja pelos "segredos de Estado". O otimismo no lançamento do projeto em 1825, sob o efeito do reconhecimento da Independência, é substituído pela apreensão com a crescente deteriorização da situação política. O último volume, de 1830, promete uma continuação que não chegou a ser publicada, certamente atropelada pelos eventos de 1831 que tornavam menos verossímil ou popular o seu retrato de Pedro I como o harmonizador da equação tacitista do equilíbrio entre liberdade e autoridade.

Um episódio de 1830 é bastante emblemático da deterioração das condições de escrita da história. A crise política e financeira do Império foi usada pelos adversários de Cairu, em especial os senadores Nicolau de Campos Vergueiro e José Ignácio Borges, como pretexto para inviabilizar a continuidade de seu projeto. Os senadores propuseram o corte dos recursos utilizados para o pagamento de um copista que auxiliava Cairu na produção de sua história do Brasil (Kirschner, 2009, p.268).

O visconde de Alcântara (João Inácio da Cunha) abria o debate na sessão de 10 de setembro de 1830 defendendo que fosse restituída a verba orçamentária destinada ao pagamento do escriturário. ${ }^{9}$ Dizia ser injusto que depois da nação ter escolhido Cairu para escrever sua história, história de que precisava, que seu auxílio fosse cortado, em especial a um homem na idade e forças de Cairu. O escriturário Estanislau de Souza Caldas recebia anualmente 365 mil reis, valor considerado muito baixo para um empregado público à época. Do lado contrário à manutenção do escriturário erguia-se o senador Nicolau Vergueiro, que

9 Anais do Senado Federal, vol. III, 10 set. 1830, p.9-16. 
apesar de insistir sobre os aspectos de economia do corte, não deixou de apontar suas dúvidas sobre a relevância e legitimidade da iniciativa:

mas diz-se: a Nação se negará a escrever a História do Brasil? Pois as histórias de todas as nações estão escritas sem as nações mandarem escrever, e não se pode mesmo esperar uma história imparcial, escrita debaixo da proteção do Governo: a posteridade é que corrige; comparando os diversos escritores, que se escreveram (sic), para formar o seu juízo: não o do escritor no tempo em que a história foi escrita; nem é de supor que seja escrita com toda a verdade, e imparcialmente; porque os homens sempre são arrastados pelas paixões, que os rodeiam sem eles mesmos sentirem: portanto isto é especulação do homem de letras, não do governo, e por isso deve suprimir-se (...). (Anais do Senado Federal, 1830, p.11)

Como se vê, motivos conceituais sobre a relação do escrito com os governos, e mesmo as condições que hoje chamaríamos epistemológicas, são levantadas no debate. Em sua defesa, Cairu afirmava que não poderia concordar com a alegação de que a história contemporânea não podia ser verdadeira. Dizia que seguiu o exemplo de outros grandes escritores contemporâneos que escreveram sobre os sucessos da Europa e América com base em documentos notórios e autênticos. Que já tinha publicado duas partes de sua obra, e que nenhuma reprimenda havia sido divulgada pela imprensa. O próprio senado não havia apontado erro ou parcialidade: "A fé histórica tem critério de verdade fundada em razão diversa da do contraditor" (Anais do Senado Federal, vol. III, 1830, p.12). Lembrava-se ainda que Tácito desacreditou as história contemporâneas do Império porque estavam contaminadas pelo medo, mas que os tempos atuais seriam outros:

A comunicação das nações, o sem número de tipografias em ambos hemisférios, impossibilitam calúnias, adulteração ou omissão dos sucessos os mais decisivos e interessantes, com a especialidade em país de 
liberal constituição. Atualmente nenhuma impostura se pode sustentar por considerável tempo, sem ser logo desmentida, por êmulos, competidores, e jornalistas. (Anais do Senado Federal, vol. III, 1830, p.12)

Ainda em sua defesa, argumentava que sua obra não era apenas ou principalmente sobre os eventos recentes da "revolução do Brasil", mas uma história geral. Vemos aqui como estava dividido entre as pressões de Pedro I e seu gabinete de enfrentar o período da Independência, e a de diversos outros setores sociais que reagiam a essa tentativa governamental de criar uma versão oficial dos eventos. Sabemos que após publicar a primeira parte de sua obra sobre os descobrimentos, Cairu foi pressionado pelo governo a abandonar seu plano original e abordar imediatamente os eventos recentes, a reação do Senado refletia essa mudança de rumo. Embora o documento que o nomeou para redigir a história fosse explícito na concentração nos eventos recentes, no debate do Senado Cairu tentou esvaziar essa interpretação dizendo: "Além de que o meu cargo foi escrever a História Geral do Brasil, e não só a história particular de sua revolução" (Anais do Senado Federal, vol. III, 1830, p.12). Em seguida, ainda procurava esclarecer o escopo dessa primeira redação:

A narrativa dos fatos políticos mais interessantes foi o objeto de meu trabalho. Coligi o disperso. Não aspirei ao ambicioso projeto da intitulada História Filosófica do país; mas também não emiti o exemplo dos arrengueiros de contos malígnos, escuras anedotas, e matérias duvidosas. (Anais do Senado Federal, vol. III, 1830, p.12)

Sua reflexão volta ao mundo antigo, criticando-o pela ausência de história contemporânea, cita o caso de reis europeus como Carlos V e os reis de Portugal que tiveram o cuidado em nomear cronistas para escrever as histórias de seus reinados, tudo para relativizar o argumento decisivo de Vergueiro de que escrever a história deveria ser tarefa particular. Em sua réplica, Vergueiro voltava ao ponto: Cairu é homem, e 
como tal falho e sujeito às influências de seu tempo. Saindo em defesa do governo, Felisberto Caldeira Brant Pontes, ${ }^{10}$ Marquês de Barbacena, reforçava o papel da liberdade de imprensa como antídoto e fiadora da verdade: "Concedo que o escritor contemporâneo pode ser influído por um partido, mas quando há liberdade os diferentes partidos se atacam, e é só por este choque, que a posteridade pode descobrir a verdade. Convém portanto que se escreva a história, e que haja copista". (Anais do Senado Federal, vol. III, 1830, p.13)

A polêmica evidencia a importância crescente da história para a vida social e política, mas também as dificuldades institucionais e epistemológicas que as novas exigências colocavam. Como garantir as condições materiais para a escrita dessa história moderna cada vez mais assentada em pesquisa documental, coleções de documentos, multiplicidade de referência, explosão de fatos? Qual o papel dos Estados constitucionais nessa tarefa? Qual a posição legítima do escritor-historiador? Qual o papel da imprensa como opinião pública e como veículo de relatos históricos?

Tudo parecia apontar para uma grande instabilidade dos relatos, algo parecido com a imagem apontada por Vergueiro de uma verdade que emerge da luta política. A imprensa como espaço de crítica era argumento nos dois lados do debate, mas isso não respondia a necessidade social de ter acesso à história de modo mais ou menos coeso. Ao mesmo tempo em que apontava a liberdade de imprensa como condição de verdade em sua obra, Cairu evocava antigos exemplos de patrocínio e mecenato de Reis e nobres. Sem qualquer patrocínio, a história, em especial a moderna, não seria possível. Mas como evitar que o patrocínio comprometesse a imparcialidade e valor do autor? Mesmo aceitando o argumento de Cairu de que a liberdade de imprensa e a luta dos partidos serviriam como instâncias críticas, fica a pergunta: por que o estado deveria financiar uma história e não muitas outras que poderiam ser escritas? A posição de Vergueiro era coerente com sua imagem de

10 Um dos negociadores do reconhecimento da Independência, Brant Pontes teria sido um dos encarregados pelo recrutamento de letrados referido na cena anterior. 
uma história que nasce do conflito. Mas esse modelo seria capaz de produzir o tipo de história completa, documentada, filosófica que se desejava então? O mundo evocado por Vergueiro estava mais próximo da situação britânica onde a escrita da história era um problema da relação entre o autor e seu público, enquanto que a posição de Cairu dependia da imagem do autor como figura quase sacerdotal, que mesmo a serviço do governo-estado era capaz de manter-se independente na busca do bem comum.

A polêmica em torno do escriturário e do papel do governo na escrita da história já apontava como era frágil a situação de um homem de letras, historiador, que dependesse da conjuntura política muito dinâmica das sociedades modernas em formação. O modelo do mecenato, mesmo emoldurado pela Razão de Estado, mostrava-se incapaz de garantir as condições necessárias para a escrita da história com as exigências do tempo, faltavam instituições mediadoras capazes de garantir legitimidade discursiva e condições materiais para o empreendimento. A abdicação de Pedro I e a grande expansão dos debates na conjuntura das Regências tornariam esses impasses ainda mais claros.

Ao mesmo tempo, a figura do autor continuava se transformando. Antologias como o "Parnaso Brasileiro", de Januário da Cunha Barbosa, publicada entre 1829 e 1832, através da coletânea de obras e notícias biográficas, ajudavam a produzir o culto moderno do autor como grande escritor (London, 2010; Westover, 2012), associando-os inclusive ao grau de civilização atingido pela sociedade, como ficaria celebrizado no ensaio de Gonçalves de Magalhães de 1836. As demandas por maior autonomia e liberdade autoral estão amplamente documentadas no período pelo contínuo lamento dos letrados acerca da falta de apoio e valorização das Belas-Letras. O cônego Januário, já na introdução de seu Parnaso, expressava a esperança de que a estabilização das lutas políticas pudesse abrir maior espaço e tempo para a vida intelectual (Araujo, 2008, p.107ss; 2009b). Como veremos a seguir, a esperança talvez não fosse muito realista, mas, ao mesmo tempo, adquiriria contornos de um primeiro projeto de ação intelectual que tinha a escrita da história em seu centro. 


\section{Cena V. 1837: Cunha Barbosa versus Justiniano JOSÉ DA ROCHA: ESCRITA DA HISTÓRIA, IMPRENSA E PARTIDARISMO}

Em sua dissertação de mestrado dedicada ao estudo da História do Brasil de John Armitage, Varella analisa uma das polêmicas envolvendo Justiniano José da Rocha e o cônego Januário da Cunha Barbosa, ${ }^{11}$ na época editores dos periódicos "Chronista" e "Correio Oficial”, respectivamente. A disputa iniciou com uma nota de Rocha datada de abril de 1837, para ele, o comerciante e historiador inglês John Armitage não teria sido imparcial em sua tentativa de escrever a história contemporânea, em especial a da Independência. A história do Brasil de Armitage seria marcada pelos interesses de grupos e partidos (Varella, 2011, p.88-89). A amizade com Evaristo da Veiga, grande articulador da Revolução de 7 de abril de 1831, teria comprometido a imparcialidade do inglês.

Em resposta, Cunha Barbosa enfatizava o contrário, destacando o fato de Armitage ter viajado pelo Brasil e estudado os fatos em documentos autênticos. Para o cônego, a Independência já era um fato feito, tinha entrado para a história, logo, estava apta a ser historiada com isenção (Varella, 2011, p.90). Barbosa valorizava ainda o uso do depoimento dos que participaram da história em posições de destaque. Avaliação semelhante - embora fundado em outros argumentos, como a qualidade sintética e expressiva da história de Armitage - podemos encontrar na resenha de Gonçalves de Magalhães publicada em maio do mesmo ano no "Jornal dos Debates", periódico editado pelo grupo da Revista Niterói, agora já retornados ao Brasil. (Varella, 2011, p.104ss)

11 A autora trás várias evidências fortes sobre a autoria de Januário da Cunha Barbosa e sua participação como editor do "Correio", mas é preciso admitir que ainda há espaço para uma dúvida razoável. Aqui tomaremos a autoria como do Cônego até que argumentos contrários indiquem outra direção. Algumas notas públicas no "Correio" ao longo de 1837 apontam para uma provável "enfermidade" do Cônego, que teria indicado por isso um substituto para suas aulas públicas de Filosofia Moral naquele ano. Em outros momentos fala-se em "editores" para o "Correio", indicando a existência de uma equipe de redação. Enfim, muito há ainda que se investigar. Como sempre, uma consulta a Lucia Guimarães ajudou também a firmar essa convicção. 
Muito já foi escrito, e ainda o será, sobre os anos de 1836-1837 e a emergência do chamado "Regresso conservador". ${ }^{12}$ Como destaca Varella, as conexões entre Armitage e o grupo liberal moderado que assumiu a liderança na organização da Regência explica muito da oposição de Justiniano (apoiador do Regresso) contra Barbosa e os jovens românticos. Entretanto, além de um capítulo da luta política da Regência, essas polêmicas revelam uma complexa história das condições de possibilidade da vida intelectual e da escrita da história no Brasil. Ao defenderem suas posições políticas, muitas vezes de modo pragmático e contraditório, esses homens de letras revelavam também suas concepções de vida intelectual, de autoria e da relação com o tipo de Estado em construção.

O combate de Rocha ao "Correio Oficial" e ao seu editor tomaria contornos ainda mais agudos ao longo do segundo semestre de 1837. Em 30 de julho, Rocha escreveria no Chronista que um periódico do governo “(...) deve ser sisudo, e decente, e não engraçado, e insultador como a antiga Mutuca". (p.2) A menção à "Mutuca" novamente trazia Januário para o centro da crítica, ele que em 1834 editava o "Mutuca Picante", jornal de luta política direta. Rocha reclamava muito do atraso do "Correio" em informar sobre as iniciativas do governo e da pouca relevância dos assuntos publicados, as matérias careciam de observações, comentários e explicações. Em outro momento, criticava um projeto que visava dar exclusivo de publicação de matérias públicas para a Tipografia Nacional. Em 17 de setembro de 1837, no mesmo "Chronista”, temos um fragmento bem revelador da natureza da disputa, Rocha escrevia:

O que é que se quer do corpo diplomático? Como deve intervir etc? Não nos quis dizer o Correio Oficial. Ora será esta a Publicidade que se deve dar aos atos do governo? Supomos que não: os redatores do Correio Oficial dirão que sim: quem terá razão? Eles decerto... Pois que realmente não há necessidade nenhuma de saber-se o que fazem os ministros, nem como nos governam. (p.2)

12 Para a relação do regresso com a temporalização e o conceito de história, ver o excelente artigo de LYNCH, 2014. 
Portanto, ao lado da luta partidária havia também o debate sobre o papel da imprensa na vida política. De modo geral, a historiografia tem valorizado a luta dos grupos partidários ou facções deixando de lado o conteúdo daquilo que estava em debate. Não quero dizer com isso que devemos fazer uma leitura ingênua e não-mediada desse conteúdo, mas entendê-lo criticamente, recuperando suas condições de possibilidade discursiva e extra-discursiva. Alguém poderá argumentar que a fala de Rocha é apenas um instrumento de luta pelo poder, que não deve ser levada a sério. Penso que a existência mesma da demanda e dos argumentos da forma como estão formulados é fato que não pode ser ignorado na história dessa sociedade.

Em 18 de setembro, após a renúncia do Padre Feijó, Pedro de Araujo Lima, o Marquês de Olinda, assumiria interinamente o governo da regência. $O$ gesto inesperado de Feijó culminou um tenso processo de desgaste, no qual periodistas de diversas cores políticas atacavam diuturnamente o governo. Como redator do "Chronista", Rocha acusava o "Correio Oficial do Rio de Janeiro" por não divulgar com transparência e atualidade as ações governamentais. A polêmica em torno da obra de Armitage era só mais um capítulo nessa disputa, de especial significado porque se identificava nela uma espécie de justificação histórica do grupo liberal moderado e do projeto iniciado no 7 de abril de 1831 .

Com a reviravolta política, Justiniano foi nomeado novo diretor justamente do "Correio" e, aparentemente, da Tipografia Nacional que o editava. Essa situação de troca de posições de poder de acordo com o revezamento de grupos políticos majoritários era algo novo e de difícil compreensão em uma sociedade que construía os contornos de uma vida política moderna. Atento ao delicado de sua posição, em 10 de outubro de 1837 Justiniano publicou uma espécie de curto editorial explicando as razões que o levaram a assumir a direção da folha governista. $\mathrm{O}$ editorial era mais uma peça em um jogo intrincado de produção de legitimidade discursiva em um período no qual as armas da luta política e intelectual modernas não estavam totalmente definidas.

Justiniano começa o curto texto afirmando ser universalmente reconhecida, nos países de liberdade de imprensa, a necessidade dos governos 
constituírem uma voz pública. Era natural que existisse um periódico para divulgar as ações do governo e defendê-las das folhas oposicionista. As folhas oficiais seriam então uma necessidade dos governos modernos. Mas, para cumprir seu papel, o "Correio", apesar de oficial, deveria ser "redigido conscienciosamente". Assim, "força é que seu redator combine em vistas com a Administração, cujos atos vai publicar, explicar e justificar".13 Portanto, era natural a mudança na redação do jornal, já que novo grupo político estava à frente do governo, grupo com o qual o antigo redator estava em contraposição. E continua, "para suceder-lhe o Governo escolheu-nos; aceitamos a missão que nos foi dada, desempenhá-la-emos com honra e dignidade, oxalá o façamos com aplauso e louvor!”. (p.332) Por fim, voltava a justificar suas críticas de véspera:

Taxamos, quando colaborador do Chronista, de - Cemitério de desmazelos - ao Correio Oficial: debaixo de nossa direção nada pouparemos para que se nos retribua igual apodo. Sempre graves e sisudos em nossos Artigos de defesa ou explicação dos atos dos governos (sic), procuraremos merecer a atenção dos leitores pela variedade de notícias estrangeiras, e de instrução úteis à indústria, às Belas Letras, e a todos os diferentes ramos de conhecimentos humanos (...). (p.332)

O editorial encerra com os topoi do esforço e dissabores a enfrentar e despender e a esperança da benevolência dos leitores. O esforço de Rocha em produzir algum tipo de autoridade discursiva entre a defesa do governo e o interesse público está registrado na própria estrutura do jornal, dividido entre uma parte "Oficial", com a publicação de atos do governo, e a de "Artigos não oficiais", na qual inclusive foi publicado o seu breve texto. Todo esse aparato parecia ser necessário para encontrar o lugar discursivo do letrado nessa nova situação entre estado, governo, sociedade civil e mercado. Não teremos espaço aqui para analisar se os leitores foram ou não benevolentes com Rocha, mas sabemos que o seu breve texto serviu de base e foi alvo da sátira e reflexão sobre o lugar do letrado no mundo moderno em construção.

13 JUSTINIANO. Correio Oficial do Rio de Janeiro (Rio de Janeiro), p.331, 10 out. 1837. 


\section{Cena Vi. Porto-Alegre versus Justiniano: A ASCENSÃo DO AUTOR ROMÂNTICO}

Em 14 de dezembro do mesmo ano de 1837, o Jornal do Comércio disponibiliza para venda em separado a caricatura "A Campanhia e o cujo", gravada a partir de desenho do jovem Manuel de Araujo Porto-Alegre. ${ }^{14}$ O que é considerado uma das primeiras "caricaturas" da imprensa periódica brasileira tem muito a dizer sobre a emergência de novos modelos de autonomia intelectual e autoral no Brasil recém-independente. A peça ironizava justamente o comportamento do novo editor do "Correio Oficial". ${ }^{15}$

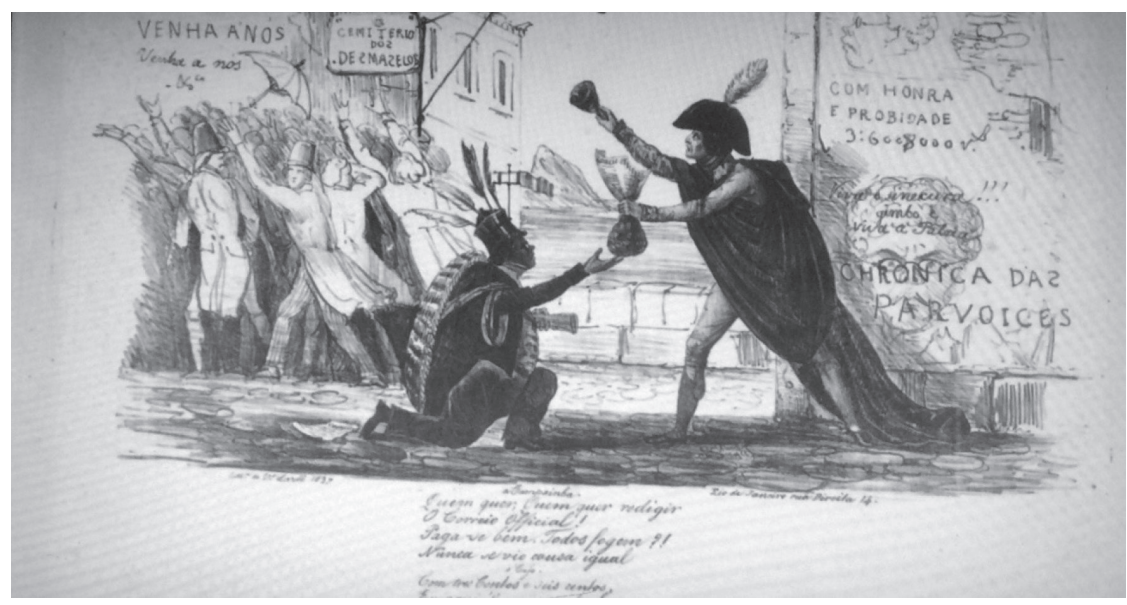

Figura 1: Manuel de Araujo Porto-Alegre. A Campanhia e o cujo. Dez. 1837. Jornal do Commercio. (venda avulsa).

14 Ver SANTOS, 2008, p.85-88; SAIDENBERG, 2013; GOMES, 1954; SALGUEIRO, 2003.

15 Durante a redação do artigo postei a imagem em meu perfil em uma rede social pedindo a ajuda dos colegas. Fui generosamente respondido por vários deles, que foram decisivos para o rumo dessa interpretação. Por isso meu agradecimento a Marcelo Abreu, Luisa Rauter, Fábio Faversani, Fábio Hering, Maria Edith, Pablo B. Souza, Thiago Lenine, Francisco Sousa e Rodrigo Turin. 
O centro da imagem é dominado por uma cena que condensa a crítica. De joelhos, aparece a figura de Justiniano José da Rocha portando objetos que o caracterizam como um letrado, um periodista, um praticante do ofício da escrita. Na cabeça, penas e um tinteiro fazem as vezes de chapéu, na mão esquerda um volume enrolado, que pode ser um manuscrito ou a edição de uma folha periódica. O conjunto denuncia a compra de "jornalistas" pelo governo. A figura oficial (seria o próprio Araujo Lima?) entrega um embrulho de folhas de jornal com moedas e vibra uma campanhia que precede o pregão, descrito na legenda abaixo da imagem:

\section{A campanhia}

Quem quer, quer redigir

O Correio oficial!

Paga-se bem. Todos fogem?

Nunca se viu coisa igual.

\section{O cujo}

Com três contos e seiscentos.

Eu aqui' stou, meu Senhor;

Honra tenho e probidade.

Que mais quer d'um redator?

$\mathrm{Na}$ direita, ao fundo, no muro de um edifício pode-se ver na parte superior a caricatura frontal de Justiniano e, na parte de baixo, a expressão "Crônica das Parvoíces", escrita em alusão ao antigo emprego de Rocha no Chronista. Essa charge era a primeira de uma dupla, a segunda, intitulada "Rocha Tarpeia", continuava o mesmo caminho de ironizar o editorial e os argumentos de Justiniano. Outras referências aos textos de Rocha no Chronista e ao editorial aparecem por todos os lados, como as expressões "Cemitérios dos desmazelos", "Com honra e probidade", "Sinecura", "Gimbo" e a cifra três contos e seiscentos mil reis $(3: 600 \$ 000)$. 


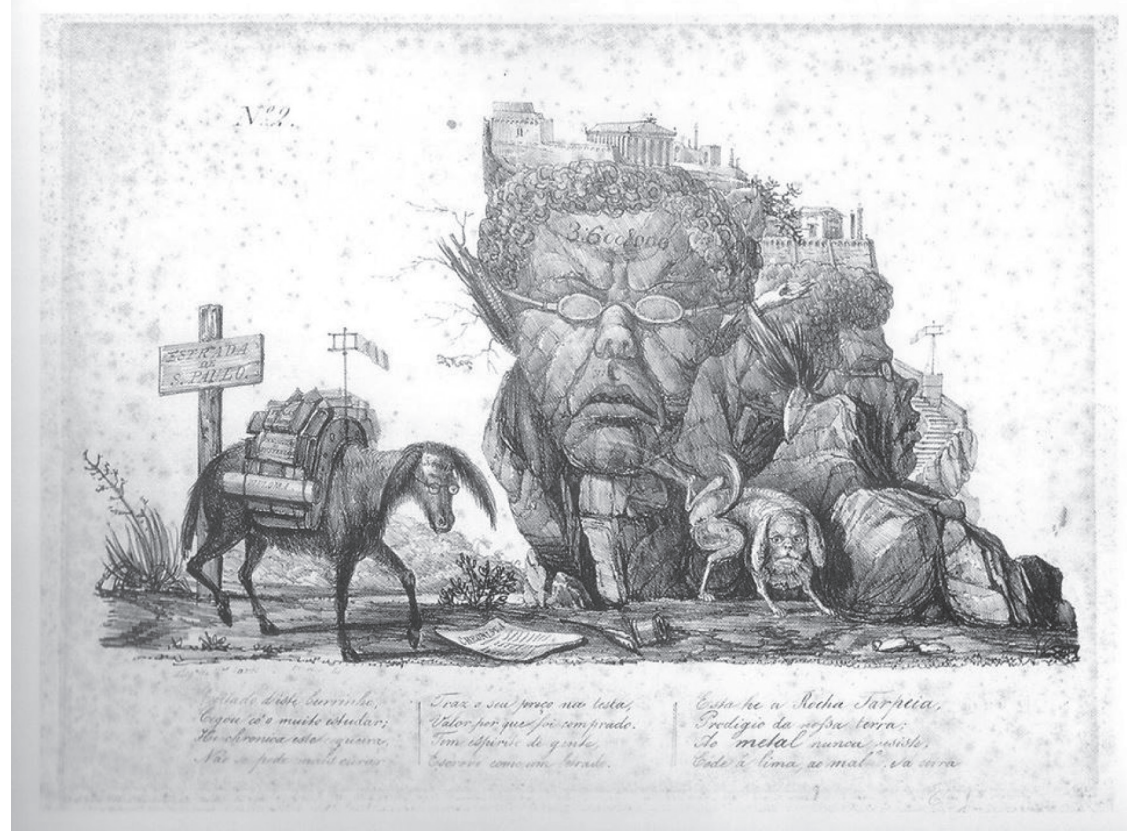

Figura 2. Manuel de Araujo Porto-Alegre. A Rocha Tarpéia. Dez. 1837. Jornal do Commercio. (venda avulsa).

Como é fácil notar, Justiniano aqui aparece satirizado em diversas imagens, de frente e de perfil formando a "Rocha Tarpeia", desenhos aliás já ensaiados na charge anterior. A referência à história clássica remete às ideias de traição, ganância e punição. A figura de Justiniano aparece ainda no burrico e no cão, ambos vestindo o inconfundível óculos redondo. Novamente o aparato letrado, sua formação em direito em São Paulo - na placa lê-se "Estrada de S. Paulo", e o valor de três contos e seiscentos reis estampado na testa da figura principal e no burrico. Como na anterior, os versos ancoram a leitura:

Coitado desse burrinho, Chegou co'o muito estudar; É crônica esta cegueira Não se pode mais curar. 
Traz o seu preço na testa,

Valor por que foi comprado.

Tem espírito de gente,

Escreve como um letrado.

Esta é a Rocha Tarpéia,

Prodígio de nossa terra;

Ao "metal" nunca resiste,

Cede à lima, ao malho e à serra

Em uma sociedade extremamente hierárquica e escravista, a figura de um homem bom, um letrado, abdicando de sua autonomia e virtude para vender-se a quem pudesse comprar, parecia escandalosa. Esse aspecto é reforçado por um evidente elemento racial, os traços mulatos de Justiniano são destacados, e, na segunda charge, associado a uma mula ou burro de carga. $O$ valor transcendental de independência que o romantismo buscava associar ao "homem e letras" era negado pelo suposto comportamento vil de Justiniano, na imagem da trova, rocha que cede à "lima" referência mais que direta ao novo regente. ${ }^{16}$

Certamente poderíamos ainda escrever alguns parágrafos desvendando as diversas camadas de referências usadas e presentes nas charges de Porto Alegre, mas tal digressão nos afastaria do que pretendemos analisar neste artigo. No lugar de simplesmente aceitar a acusação de Porto Alegre, como fez boa parte da crítica, temos que considerar seriamente a posição de Rocha ao refletir sobre o lugar de uma imprensa pró-governo em uma sociedade livre, as condições de autonomia negociada que esse jornalista oficial reivindicava. O confronto entre Porto Alegre e Justiniano José da Rocha é mais do que apenas um episódio da encarniçada luta política do

16 Em sua dissertação, QUEIROZ, 2011, p.19, estuda a troca de correspondência entre Rocha e Paulino José Soares de Sousa sobre as condições para a criação de um jornal comprometido com certo programa ministerial. O material mostra a complexidade dessas negociações, que não envolvia apenas a "compra" do jornal, mas a garantia do seu autor contra o inevitável desgaste de sua posição. 
período regencial, ele documenta um ponto de inflexão importante na história da formação do historiador como autor moderno. ${ }^{17}$ Ao denunciar o caráter supostamente mercenário da ação de Rocha, Porto Alegre evocava uma concepção romântica de autoria que valorizava a originalidade e a inspiração, mas também confirmava as reclamações do Cônego Januário da inexistência de um espaço institucional letrado. Certamente não era acidental que dois dos principais nomes da Niterói estivessem envolvidos nessas disputas ao lado justamente de Januário da Cunha Barbosa.

Ao fundo desse debate questões como a definição de direitos autorais e da forma de financiamento da vida intelectual estavam em questão. Essa relação mais direta com o mercado, ensaiada por Rocha, seria contraposta à ideia de uma vida intelectual autônoma subsidiada pelo poder público. ${ }^{18}$ Como analisou Cilza Bignotto, nessas primeiras décadas do século XIX, vemos a oposição entre uma concepção de produção do impresso predominantemente artesanal, como um serviço a ser prestado, e outra que vai se concentrar em conceitos como inspiração, originalidade e subjetividade (Bignotto, 2007, p.52). A imagem de Justiniano nas charges de Porto Alegre certamente lembrava ao leitor brasileiro da época a figura dos negros vendedores de livro, que de balaio na cabeça mascateavam os últimos impressos (Bignotto, 2007, p.68). A jovem geração romântica certamente não queria se confundir com esse mundo ambíguo em que o letrado era visto como uma espécie de trabalhador mecânico. Mas, novamente, o debate proposto por Rocha não era esse, o que refletia era sobre os novos lugares e oportunidades abertas pelo jogo da imprensa livre. ${ }^{19}$ Mas como demonstrou Lucia Guimarães, a figura de Rocha voltaria a envolver-se em polêmicas sobre a venalidade do

17 Marcelo Rangel tem demonstrado como o Romantismo de Magalhães embute uma filosofia da história do Brasil e um diagnóstico da sociedade brasileira que ao denunciar o egoísmo das elites preparava o lugar e um projeto pedagógico letrado. RANGEL, 2013.

18 Sobre a evolução da legislação sobre direito autoral no Brasil do Oitocentos, ver BIGNOTTO, 2007, p.28ss.

19 "Essas duas figuras de autor - aquele que escreve por amor à arte, e aquele que pretende viver da pena (ou pelo menos vender algo do que produz com ela) - vão atravessar o século e chegar até os anos em que Monteiro Lobato foi editor, para não dizer que existem até hoje". (BIGNOTTO, 2007, p.74). 
intelectual, dessa vez, no contexto da política de Conciliação envolvendo a autoria de seu mais conhecido panfleto. (Guimarães, 2005, p.3-8)

\section{CENA VII. À guisa de CONCLUSÃo: A CRIAÇÃO DO IHGB E O CONFRONTO DE AUTONOMIAS}

Alguns meses depois dos episódios narrados acima, em 1838, Januário da Cunha Barbosa e outros letrados se uniriam para criar o Instituto Histórico e Geográfico Brasileiro. Enfatizando o caráter iminentemente letrado do novo espaço, seus fundadores procuravam afastar o instituto do mundo tumultuado da imprensa periódica. A revista trimestral, inclusive pelo seu formato mais próximo do livro, criava um espaço mais controlado para a produção histórica. Lance fundamental para produção de um espaço disciplinar, ou do ethos do historiador (Turin, 2009), a criação do IHGB, no entanto, não significou o fim das polêmicas ou o desaparecimento de modelos competitivos de escrita da história. De certa forma, os arranjos competitivos entre uma historiografia disciplinar e o que podemos chamar de "historiografias populares" é um traço de longa duração. Zeloso pela não partidarização da escrita da história, os membros do IHGB se confrontariam, já nos anos imediatos à fundação, em duas outras polêmicas que não teremos tempo aqui de desenvolver, mas que são bem conhecidas, contra Francisco Solano Constâncio e o General Abreu e Lima. ${ }^{20}$ Em ambas criticava-se a pouca originalidade, o plágio, a ausência de crítica documental e a visão partidária desses relatos. Nas palavras de Varnhagen, esses autores seriam "especuladores" cuja existência dependia de interesses extra-científicos, sugerindo, naturalmente, os interesses partidários e comerciais/editoriais. ${ }^{21}$

20 A dissertação de Thamara de Oliveira Rodrigues, desenvolvia na UFOP, nos ajudará a compreender a dimensão da história na obra de Constâncio. Para uma prévia, ver RODRIGUES, 2014, p.165-182.

21 O tema parece que vai se tornando um topos. Na introdução de seu "Quadros Históricos de Portugal", de 1847, Antônio Feliciano de Castilho escrevia: "Não é um pensamento de livreiro, não é uma especulação comercial, é uma concepção de grande utilidade nacional, concepção de alta moral política”. (p.I). 
Com as primeiras publicações do Instituto, ainda em 1838, veremos na imprensa reclamações acerca dos direitos autorais. No Chronista, após diversos elogios a uma memória do Visconde de São Leopoldo publicada pelo IHGB, o redator denuncia:

Ora, em parte se verificaram as previsões do Instituto: a memória foi muito bem recebida do público; mas, enquanto se principiava a vendê-la, duas folhas diárias dessa corte - para que ela fosse mais lida - sem cerimônia alguma a estampam em suas colunas!.. Qual será pois o assinante destas folhas que vá comprar um exemplar da memória do Instituto? E não ficará esta associação lesada nos seus interesses? Mas, diz-se, para ser mais lida: mas quem vos pediu tamanho obséquio? Recomendou-vos o Instituto que fizésseis esse sacrifício em seu favor? E demais, porque não dais vossos jornais de graça? Eu vos afianço que eles seriam mais lido do que o são presentemente. (O Chronista, n.303, p.1213, 16 mar. 1838). (Grifo nosso)

Já na edição 305 do mesmo Chronista, o próprio IHGB publicaria um anúncio relatando o abuso cometido contra a sua primeira memória, editada pela casa Laemmert. A nota, assinada por Emílio Joaquim da Silva Maia, segundo secretário do Instituto, informava que em deliberação interna, decidiu-se que "se a dita memória, ou outra qualquer produção literária cuja propriedade lhe pertença ou venha pertencer de ora em diante, for impressa ou reimpressa por pessoa que para isso não for autorizada pelo Instituto, será essa pessoa perseguida em juízo para que lhe seja imposta a pena do art. 261 do código criminal" (O Chronista, n.305, p.1222, 23 mar. 1838). Em seguida vinha transcrito o referido artigo do código de 1832 .

Apenas a título de sistematização, propomos reunir esse conjunto de fenômenos na tipologia abaixo, deixando claro seu caráter provisório. A tipologia visa dar coerência a fenômenos históricos complexos e multivalentes, ela se justifica aqui pela sua capacidade em tornar visíveis movimentos estruturais que são de difícil visualização direta nos fenômenos e não como uma descrição empírica de casos, no limite, nenhum dos casos estudados poderia ser simplesmente enquadrado de um lado ou outro da tabela. 


\begin{tabular}{|c|c|}
\hline Regime compilatório & Regime disciplinar \\
\hline $\begin{array}{l}\text { Apoio forte do sistema de subscrição } \\
\text { e editorial. }\end{array}$ & $\begin{array}{l}\text { Subsídio estatal direto ou indireto. } \\
\text { Formação de Sociedades/instituições. }\end{array}$ \\
\hline $\begin{array}{l}\text { Preocupação com a síntese e a oferta } \\
\text { de uma versão menos documentada }\end{array}$ & $\begin{array}{l}\text { Padrão erudito. Valorização da crítica e } \\
\text { da autoridade do pesquisador/erudito. }\end{array}$ \\
\hline $\begin{array}{l}\text { Presença de linguagem sentimental } \\
\text { em algumas dessas obras. }\end{array}$ & Formação de um “decoro” especializado. \\
\hline Resistência à erudição moderna. & Fusão de erudição, filosofia e narrativa. \\
\hline $\begin{array}{l}\text { Maior presença de padrões/referências } \\
\text { clássicas. }\end{array}$ & $\begin{array}{l}\text { Abertura para os padrões conceituais } \\
\text { modernos e os limites do discurso } \\
\text { histórico. }\end{array}$ \\
\hline $\begin{array}{l}\text { Demandas locais/regionais de } \\
\text { identidade e justificação política. }\end{array}$ & $\begin{array}{l}\text { Centralidade da História Geral } \\
\text { Nacional }\end{array}$ \\
\hline $\begin{array}{l}\text { Fusão entre documento e relato - } \\
\text { texto arquivo. }\end{array}$ & Separação entre documento e relato. \\
\hline Escrita como ação política direta & $\begin{array}{l}\text { Escrita como formação/informação } \\
\text { (ação política indireta). }\end{array}$ \\
\hline
\end{tabular}

Por fim, o que pode aproximar as iniciativas editoriais de autores como Beauchamp, Beaumelle, Armitage, Constâncio, Abreu e Lima era uma relação estreita com o emergente mercado editorial e um público leitor não especializado. Com o IHGB e as transformações aceleradas do romantismo literário, um novo modelo de autonomia intelectual se fortaleceria, impondo com ele um padrão disciplinar fundado na especialização, despolitização (entendida como não-partidarismo) e um maior controle interno, dos considerados pares, da atividade do historiador. Para este padrão disciplinar era vital a aliança com o Estado liberal em consolidação, já que para o modelo do "letrado-intelectual-jornalista" 
a relação com o mercado do livro emergente representou um modo alternativo de escrever história, mais aberto às influências da luta partidária e das flutuações e permanências do "gosto" de um público não especializado. Esses dois regimes de autonomia continuarão, ao longo do século, suas relações de competição e convergências.

\section{Agradecimentos}

Esta pesquisa foi realizada no âmbito do Projeto integrado Variedades do Discurso Histórico Moderno, financiado pela Fapemig no programa de apoio a grupos emergentes, Pronem. Além disso, está associado ao projeto de pesquisa que desenvolvo como bolsista de produtividade do CNPq e como bolsista do programa Pesquisador Mineiro da Fapemig. Agradeço aos docentes e demais pesquisadores do NEHM - Núcleo de Estudos em História da Historiografia e Modernidade - pelo diálogo rigoroso e estimulante. Além disso, agradeço aos diversos orientando(a)s que ao longo desses 10 anos de UFOP desenvolveram e desenvolvem pesquisas, na UFOP ou em outras instituições, sem as quais essa tentativa de síntese não seria possível.

\section{REFERÊNCIAS BIBLIOGRÁFICAS}

ABBATISTA, Guido. The Business of Paternoster Row: towards a Publishing History of the "Universal History" (1736-65). Publishing History, n. 17, p.5-50, 1985.

ABBATISTA, Guido. The English Universal History: publishing, authorship and historiography in an European project (1736-1790). Storia della Storiografia, n. 39, p.103-108, 2001.

ARAUJO, Valdei Lopes de. A época das revoluções no contexto do tacitismo: notas sobre a primeira tradução portuguesa dos Anais. Estudos Ibero-Americanos, vol. 36, n. 2, p.343-365, 2010b.

ARAUJO, Valdei Lopes de. A Experiência do Tempo: conceitos e narrativas na formação nacional brasileira (1813-1845). São Paulo: Hucitec, 2008. 
ARAUJO, Valdei Lopes de. As transformações nos conceitos de literatura e história no Brasil: rupturas e descontinuidades (1830-1840). Saeculum, vol. 1, p.49-68, 2009b.

ARAUJO, Valdei Lopes de. Cairu e a emergência da consciência historiográfica no Brasil (1808-1830). In: NEVES, Lucia Maria Bastos Pereira das, et alii. Estudos de historiografia brasileira. Rio de Janeiro: FGV, 2010. p.75-92.

ARAUJO, Valdei Lopes de. Formas de Ler e Aprender com a História no Brasil Joanino. Acervo, vol. 22, n. 1, p.85-98, 2009.

ARAUJO, Valdei Lopes de. História da historiografia como analítica da historicidade. História da Historiografia, n. 12, p.34-44, 2013.

ARAUJO, Valdei Lopes de. O século XIX no contexto da redemocratização brasileira: a escrita da história oitocentista, balanço e desafios. In: ARAUJO, Valdei Lopes de; OLIVEIRA, Maria da Glória de (orgs.). Disputas pelo Passado: história e historiadores no Império do Brasil. Ouro Preto: EDUFOP, 2012. p.136-924.

ARAUJO, Valdei Lopes de. Observando a observação: sobre a descoberta do clima histórico e a emergência do cronótopo historicista, c. 1820. In: CARVALHO, José Murilo de; CAMPOS, Adriana Pereira (orgs.). Perspectivas da cidadania no Brasil Império. Rio de Janeiro: Civilização Brasileira, 2011. p.281-304.

ARAUJO, Valdei Lopes de; PIMENTA, João Paulo. Verbete História. Ler História, vol. 5. p.83-96, 2008.

BAÁR, Monica. From general history to national history: the transformations of William Guthrie's and John Gray's: A general History of the World (1736-1765) in continental Europe. In: STOCKHORST, Stefanie. Cultural Transfer through Translation. Amsterdam-New York: 2010. p.63-82.

BEVERNAGE, Berber. History, Memory, and State-Sponsored Violence: Time and Justice. New York: Routledge, 2012. (Edição Kindle)

BIGNOTTO, Cilza Carla. Novas perspectivas sobre as práticas editoriais de Monteiro Lobato (1918-1925). Tese (Doutorado em Teoria e Crítica Literária) - Universidade Estadual de Campinas. Campinas, São Paulo, 2007. 
CEZAR, Temístocles. Escrita da história e tempo presente na historiografia brasileira. In: DUTRA, Eliana de Freitas (org.). O Brasil em dois tempos. História, pensamento social e tempo presente. Belo Horizonte: Autêntica, 2013. p.29-46.

COSTA, Wilma Peres. Entre tempos e mundos: Chateaubriand e a outra América. Almanack Braziliense, n. 11, p.5-25, maio 2010.

DAVIES, Martin L. Imprisoned by History: Aspects of Historicized Life. New York: Routledge, 2012. (Edição Kindle)

DINIZ, Bruno. Da Restauração à Regeneração: Linguagens Políticas em José da Silva Lisboa (1808-1830). Dissertação (Mestrado em História) - Universidade Federal de Ouro Preto. Mariana, 2010.

GOMES, Eugenio. A Caricatura na Imprensa do Rio de Janeiro. Rio de Janeiro: Biblioteca Nacional, 1954. (catálogo)

GUIMARÃES, Lucia Maria Paschoal. Ação, reação e transação: a pena de aluguel e a historiografia. ANPUH - XXIII Simpósio Nacional de História, vol. 3, p.1-8, 2005.

GUMBRECHT, Hans Ulrich. Uma rápida emergência do "clima de latência". Topoi, vol. 11, n. 21, p.303-317, 2010.

KIRSCHNER, Tereza Cristina. José da Silva Lisboa, Visconde de Cairu: itinerários de um ilustrado luso-brasileiro. São Paulo: Alameda, 2009.

KIRSCHNER, Tereza Cristina. Um pouco de historiografia: a representação do passado colonial brasileiro a partir da independência. Anais do XXVI Simpósio Nacional de História - ANPUH, p.1-33, jul. 2011.

LINK, Anne-Marie. Engraved Images, the Visualization of the Past, and Eighteenth-Century Universal History. Érudit, n. 25, p.175-195, 2006. LONDON, April. Literary History Writing, 1770-1820. London: PalgraveMacmillan, 2010.

LYNCH, Jack. Orientalism as Performance Art: The Strange Case of George Psalamanazar. Rutgers University, Delivered 29 January 1999 at the CUNY Seminar on Eighteenth-Century Literature. Disponível em: http://andromeda.rutgers.edu/ jlynch/Papers/psalm.html. Acesso em: 21 fev. 2013.

MELTON, James Van Horn. The Rise of the Public in Enlightenment Europe. Cambridge: Cambridge University Press, 2001. (Edição Kindle) 
NEVES, Lucia Maria Bastos Pereira das. Impressores e livreiros: Brasil, Portugal e França, ideias, cultura e poder nos primeiros anos do Oitocentos. RIHGB, vol. 172, n. 451, p.231-246, 2011.

NOVICK, Peter. That Noble Dream: The 'Objectivity Question' and the American Historical Profession. Cambridge: Cambridge University Press, 1988.

PIMENTA, João Paulo Garrido. Passado e futuro na construção de uma história do Brasil no século XVIII. In: ARAUJO, Valdei Lopes de; NICOLAZZI, Fernando; MOLLO, Helena (orgs.) Aprender com a história? O passado e o futuro de uma questão. Rio de Janeiro: FGV Editora, 2011. p.115-130.

QUEIROZ, Tatiane Rocha de. Do regressismo ao conservadorismo do periódico "O Brasil" (1840-1843). Dissertação (Mestrado em História) Universidade do Estado do Rio de Janeiro. São Gonçalo, 2011.

RAMOS, André da Silva. Robert Southey e a Experiência da História de Portugal: Conceitos, Linguagens e Narrativas Cosmopolitas (1795-1829). Dissertação (Mestrado em História) - Universidade Federal de Ouro Preto. Mariana, 2013.

RANGEL, Marcelo de Mello. Teria o Império do Brasil um destino trágico?. Revista Da Academia Brasileira de Letras, n. 75, p.225-236, 2013.

RODRIGUES, Thamara de Oliveira. Crise e Independência na historiografia portuguesa: a História do Brasil de Francisco Solano Constâncio. In: GARCIA, Fernando Gomes; MENDES, Breno; VIEIRA, Andréa (orgs.). Teoria da História em Debate: modernidade, narrativa, interdisciplinaridade. Jundiaí, SP: Paco Editorial, 2014. p.165-182.

ROSA, Giorgio de Lacerda. A suprema causa motora: o providencialismo e a Escrita da História no Brasil (1808-1825). Dissertação (Mestrado em História) - Universidade Federal de Ouro Preto. Mariana, 2011.

SAIDENBERG, Ivan. A história dos quadrinhos no Brasil. Nova Iguaçu: Marsupial editora, 2013.

SALGUEIRO, Heliana. A comédia urbana: de Daumier a Porto-Alegre. São Paulo: Fundação Armando Alvares Penteado, 2003.

SANTOS, Renata. A imagem gravada: a gravura no Rio de Janeiro entre 1808 e 1853. Rio de Janeiro: Casa da Palavra, 2008. 
TURIN, Rodrigo. Uma nobre, difícil e útil empresa: o ethos do historiador oitocentista. História Da Historiografia, n. 2, p.12-28, mar. 2009.

VARELLA, Flávia Florentino. Da impossibilidade de aprender com o passado: sentimento, comércio e escrita da história na "História do Brasil" de John Armitage. Dissertação (Mestrado em História) - Universidade de São Paulo. São Paulo, 2011.

VIANNA, Hélio. A primeira versão da Introdução à História dos principais sucessos políticos do Império do Brasil, do Visconde de Cairu. Revista de História, vol. XXVI, n. 53, p.35-52, jan./mar.1963.

WESTOVER, Paul. Necromanticism: Travelling to Meet the Dead, 1750-1860. London: Palgrave-Macmillan, 2012.

ZAMMITO, John. Historians and Philosophy of Historiography. In: TUCKER, Aviezer. A companion to the philosophy of history and historiography. London: Willey-Blackwell, 2009. p.63-84.

ZANDE, Johan Van der. August Ludwig Schlöser and the English Universal History. In: BERGER, Stefan; LAMBERT, Peter; SCHUMANN, Peter. Historikerdialoge: Geschichte, Mythos und Gedächtnis Im Deutsch-britischen Kulturellen Austausch 1750-2000. Göttingen: Vandenhoech Ruprecht, 2003. p.135-156. 